\title{
Discussing the design through drawing. Transitional desire and procedural trajectories
}

Design represents the commitment of the artificial with nature - the artifact as symbolic cultural representation. Herein, drawing is the skill activity of the designer as renewed desire it transforming the world. Therefore, drawing is the material of design as medium of the representation, such as technical and interpretive expression of the author's imagination from an external program (brief).

Hence, we propose drawing as a path performed by author's desire that symbolically reveals the subject of design in a specific level. The artifact as primordial income for the conceptual design process comes out of the drawing tools as practice that elevates the cultural representation. The pattern of drawing can be, symmetrical or asymmetrical, the link that joins two levels of the artifact, instrumental and critical, it becoming the basis for design's narrative.

In this case, drawing skills convey and supporting the cultural expression showing design as a particular and symbolic cultural artifact.

As context we refer the analysis of representative designers in the Portuguese geographic and cultural environment. We hypothesized that cultural and symbolic features result according to the artifact's identity.

We seek the goal of the analysis according to the significance of drawing in the discipline of design. This research intends to scientifically integrate the ontological analysis of drawing in relation to design through the presented Portuguese examples.

keywords design, drawing, representation, process

\section{Introduction - conceptual context}

In our case, we consider that drawing inscribes the creative and symbolic understanding of the design subject, through the poetic present on the artifact. We believe that foresight may be reflected in the drawing as a tool but mostly as poetic field. Treating drawing as double referent: understanding and outcome of the design process.

Many of the methodologies consider the general problem of design as an idea execution and the process from which the project raises a set of problems to overcome in order to execute the idea.

In our case, the design does not stem from this problem's issue as well as it does not consider the process through a pre-established formula which goal leading to an action. The design's subject problems we will be explored by drawing. It means that we attach 
to drawing the capability to understand, imagine and communicate design artifacts. Francisco Providência drawings (fig.1.a) don't represent the idea but it was established as the movement inspired by it. The idea follows the objective meaning represented by drawing: on the sheet by designer' hand it operates symbolically. Through the author's desire, the object of design is a laconic presence of the artificial by the symptomatic presence of the drawing nature. Therefore, the Francisco Providência drawings transmit the minimal attendance of the object. The designer attends in the drawing the laconic presence of the object further the virtuous drawing as enlightening in the project. As stated by Federico Zuccari, Francisco Providência drawing appears as "first internal motion the beginning and the end of our operations" (Zuccari in Quici, Tracciati d'invenzione, Torino, UTET, 2004, p. 57). The allure of the drawing results from the formal semblance of the program (brief), it is developing from the project into two behaviours: rational and emotionally. The author's rationality derives the deepen design thinking and through the emotional character reaches the formal organization of the design project.

Drawing puts into action the project designing. We recognize that designing is not making the object'; however, the assessment of the designed object will be leading by the possibilities of the project representation.

We consider that the performance of the design thinking through drawing is able to raise the understanding and imagination of the object. In the action of drawing is found the possibility of freedom praticed by individual designers, freedom necessarily "rooted" to the project, which will make of it an involved freedom as we believe to be any action. In this projectual hypothesis drawing 'internalizes' the idea through processual way of making.

\section{Interpretative context}

As Fernando Poeiras points out, through the statement by Raymond Ruyer, "creation is a new resolution, always involved in a problem" (Poeiras, Cadernos PAR01 2006: 37). For Ruyer, in the projectual scope there are 3 levels of consciousness: 1. "foresightful"z consciousness - vague idea points out the sense of the problem, 2. schematic consciousness - conveys the formal consistency of the solution to the problem and 3 . operative consciousness - assuring the idea procedure. In this case the triangulation of the projectual scope of the idea problematization it will be in correspondence to the triangulation program - authorship - technology setting of design33. Thus the "foresighful" consciousness arise from the program, the schematic consciousness of authorship and the operative consciousness of technology ${ }^{4}$.

In our analysis drawing (pre) exists as multidisciplinary function through the triangular representation classification - representation - imagination ${ }^{5}$ (Partenone 1984-1990: 36) and it articulates the consistency between projectual consciousnesses.It may reach complementarity in (Table 1):

\footnotetext{
'Although these two ways of doing are traditionally dissociated, its association is acknowledged in certain examples of contemporary design.

${ }^{2}$ in the original "pressentinte", Portuguese neologism indicating ability to foresee or "fore-sense" the future.

3 Definition proposed by Francisco Providência.

${ }^{4}$ However it is important to state that the "consciences" and the projectual "partialization" are neither isolated nor absolute values. The schematic thought does not correspond to reality. We seek to achieve a spatial arrangement that allows us to thinking about drawing in the specific scope of the design project. ${ }_{5}^{5}$ Representation means to make visible the intention of the project. Classifocation means attribution of meaning in the world of objects. Imagination means to proceed with the intention.
} 


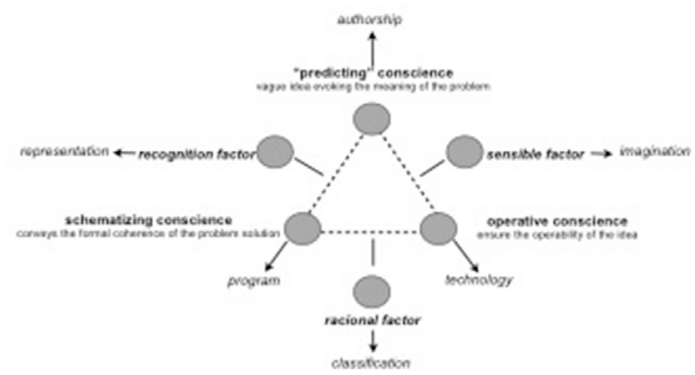

In this case, drawing practice in design may be defined as recognition value according to representation, sensitive value according to imagination and the rational value according to classification.

In extreme, we may consider that drawing the project of design implies a thinking scope attending to the understanding of the subject and an imagistic scope testing the imagination about it. This duality let in the representation of the project.

The images evaluation follows from the relationship of them in the author's vision. Images come together according to forthcoming and withdrwall in its perpetual motion. Each image search for the next to appease the desire of knowing and calls for freedom in discarting the previous.

However, the purpose of project's drawing is not the correspondence between imagination and knowing through the expression of models.

The experience of drawing complies with the goal of the design. However, to consider the resolution of design project through drawing practice it is not the same "as thinking about resolution of the project through drawing irresolutions" as referred by Fernando Poeiras. "The "wise" use of drawing does not enhance the operative power of drawing: its capability to question or experiment" (Poeiras, Cadernos PARO1, 2006: 39). From the intentionality, there is a leading possibility of the drawing irresulutions to proceed with the project. The tricky drawing doing by designer's hand, the internal imbalance between resolution and tools, and external between desire and being is also the true sign of the representation. Regarding art it is embracing the artificial so that drawing it deals into realm through the reality of representation. Regarding design it deals with the internalization of projecting problems onto drawing so that it may constitute an experimental field capable to showing the object of design.

In this case, the productive ability of project's drawing may be tthrough like the imbalance between drawing and its models. For example (Table 2):

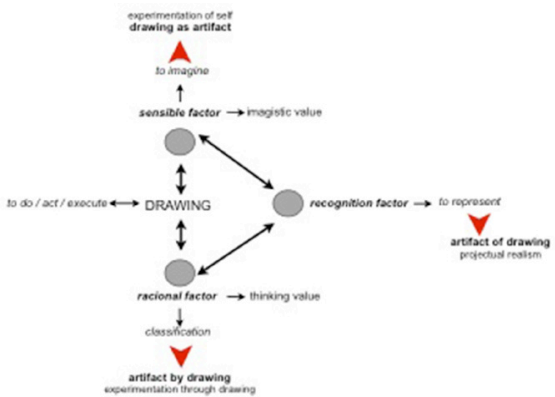

Table 1.

Articulation of projectual awareness and drawing.

Table 2.

Project drawing productive capacity 
The productivity will depend on the experimentation that drawing is able to provide about the design artifact, on the degree of experimentation itself, on how it relates to other disciplines and how it allows its own uncertainties and irresolutions.

The problem's relevance is disclosed in the shape drawing as a rhetoric function underlying the operative system of the processual designing. The Miguel Rios work (fig. 1.b) can starts from the mapping of the different types of images. Maps that are a huge set of images whose intent is designing the object. These images are the subject of the project: they can be photographs, newspaper and magazines clippings, details or others. The images have different sizes and different approaches. They remain as research. Personal diagram. They are a schematic thinking, a self way of thinking. Drawing goes beyond the graphical feature, it appears as image. In this case, the collected images bear as a "binder memory, a way to draw the concept", as he said.

The project stems from a polysemic set of drawings evolving throughout the process onto a state of monosemic assumptions. Drawings, however, are the author's expression and way of knowing. In this case, we seek to:

1. understanding design as poetic expression dwelling by the designer's practice seeking to expand the field of the artificial in the interaction between the possible and the thinkable, it constitutes the assumptions to thinking the future (innovation);

2. innovation in design has a poetic nature. This innovation depends on the set of emotional markers (author's own experiences) that determine the analytical dimension of intelligence, through aesthetics, ensuring the symbolic innovation on the new artifact; 3. when sensitive thinking, aesthetically, design issues, are purpose by the object goal, intents of a drawing stemming from the author's desire.

4. therefore, it will be required treating the symbolic innovation features as the representation alter-ego.

\section{Conclusion}

We believe it will be helpful and honest to reflect on drawing in the scope of design by stating the limits of its practice, both in its effectiveness of doing and as the disciplinary 'aid' within designing. Also as referred by Fernando Poeiras, the idea that "Design may be the drawing of the object" will be as limiting to drawing as to the design project, remarking the distance from its performance: the artifact (material object produced).

To identify drawing with design is to diminish both drawing and design. Project's drawing merely understood as representation, narrowed the construction in the scope of production, or purely to be an image, through the speculative function of the idea, or else as selective classification of the hypotheses through rationality is decrease. In a more comprehensive way of knowing drawing is a pratice able to bring into the design project capital gains originating out of it: 1. from other disciplines or makings; 2. from tools of drawing, by its skills ; 3 . from its heteronomy using an external model for projectual development.

Project's drawing uses other fields of experimentation, its technical skills treating external and internal problems and its heteronymous expression conserning the subject model. Therefore, we seek to set drawing as design thinking, doing by irresolutions and uncertainties, composed by crossings, balances, displacements, reapropriations, articulations, transpositions, detours, migrations and marks, enabled by gesture of the 
designer (project maker).

Drawing physically and mentally practicing it. In this case, drawing does not precede the idea, neither does it represents itselves, instead it appears in the movement of it generating the figure. According to Fernando Brízio (fig. 1.c) is very important to perform the implementation of the object, it is evaluates by procedural methods of design as a body action. The object appears as a real formalization of the design project. In this case, the design process is intertwined with the project drawing. The object of representation are decomposed in order to equate the project. The design is solved decomposing the artefacts belonging to the project. The analysis derives from drawing as a way of knowledge: "the world is a dwell huge drawing", the designer said. The author concerns the understanding of the world as an anthropological reference, considering that man invented and establishing goals in order to stay on earth. Fernando Brízio detaches the object of design as a specific option of the drawing, "we live in an artificially designing world. Everything is designed. By drawing, the design objects, conforming our bodies and our experience of the world", he said.

The idea (thinking) results from the objective assertion of drawing - through the designer body. Therefore, drawing is stating for freedom, it claims for the possible of contradictions, paradoxes that developing the design subject, as "event memory" (Badiou on Silva, Cadernos PARoz 2009: 134).

Author's production results from the critical and the self interaction with place and itselves. The individual act of the designer is, symbolically, inscribed as social memory of the event in the space and time that enabled its production. The design symbolic features will result, as proposed by Rodrigo Silva, from the statement of "existence of a free-space as possibility of creation, as shelter space for human native indeterminacy and impropriety, as circulation of human transitivity made from a frame of spaces and times." (Silva, Cadernos PARo2 2009:137).

In this case, drawing is symbolically intermediate on and about the place and time whose its happen as reaction of drawing's prodution. "Thought, acted upon by space, the creative processes that are inscribed upon places, delimiting the spatial syntax of the world, those are the grammar of places to come" (Silva, Cadernos PARo2 2009: 137). Hence, too, drawing as matter for design invention.

In this article we are showing only few specific case studies from among many others that could be represented. Portuguese design seeks to confirm the poetic features founded on drawing as the compatible observation between the self and the world, which means, practically understanding the artificial within the natural.
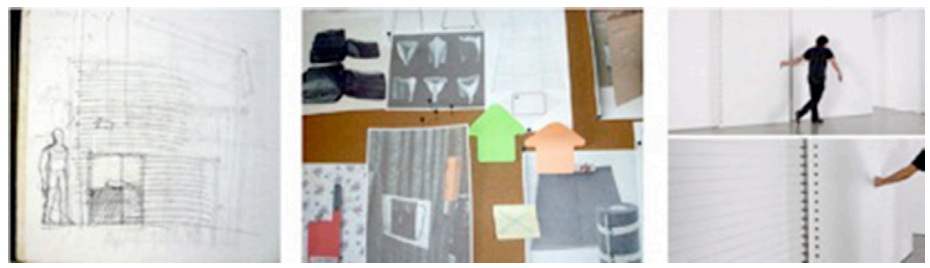

Figure 1. from left to right, (a) Providência, F. (2006), Sketches; (b) Rios, M., (2007) System $2 k o 7 ;$ (c) Brízio, F., (2007), Sketching door. 


\section{Bibliography}

Belardi, P. (2004) Brouillons d'architects: una lezione sul disegno inventive, Melfi: Librìa. Cicalò, E. (2010) Immagini di progetto. La rappresentazione del progetto e il progetto della rappresentazione, Milano: Franco Angeli.

Cook, P. (2008) Drawing. The motive force of architecture, England: John Wiley \& Sons, Lda. Côrte-Real, E. (ed.) (2010) The Triumph of Design. O Triunfo do Desenho, Lisboa: Livros Horizonte I UNIDCOM/IADE.

Garner, S. (2008) Writing on Drawing, Bristol, UK / Chicago, USA: Intellect Books. Partenope, R. (ed.) (1984-1990) Nel disegno. Materiali di un corso di disegno e rilievo della facoltà di architettura di Roma, 1984-1990, Roma: CLEAR.

Poeiras, F. (2006) 'Pragmáticas do desenho em Design', Cadernos PAR - Pensar a Representação, Leiria: ESAD.CR, Instituto Politécnico de Leiria, pp. 35-47.

Quici, F. (2004) Tracciati di invenzione. Euristica e disegno di architettura, Torino: UTET. Robbins, E. (1997) Why architects Draw, Cambridge, Massachusetts, London, England: The MIT Press.

Silva, R. (2009) 'O pensamento da deslocalização', Cadernos PAR - Pensar a Representação, Leiria: ESAD.CR, Instituto Politécnico de Leiria, pp.124-137.

\section{Acknowledgements}

This work is funded by national funds through the Foundation for Science and Technology - FCT - in the scope of project PEst-OE/EAT/UI4057/2014.

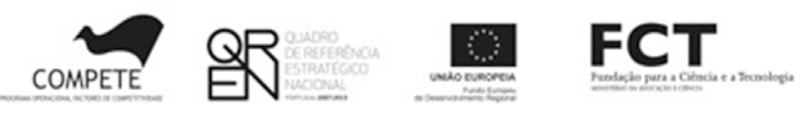

